\title{
ONLY SEED SIZE MATTERS FOR GERMINATION IN DIFFERENT POPULATIONS OF THE DIMORPHIC TRAGOPOGON PRATENSIS SUBSP. PRATENSIS (ASTERACEAE) ${ }^{1}$
}

\author{
TAMARA VAn MÖlKen, Linda D. JorRitsma-WienK, ${ }^{2}$ \\ PaUl H. W. VAN HoEK, AND Hans de KroON
}

Department of Experimental Plant Ecology, Radboud University of Nijmegen, Toernooiveld 1, 6525 ED Nijmegen, The Netherlands

\begin{abstract}
Many studies have focused on the ecology of seed dimorphism, the production of two seed types by a single plant. Morphology and seed size are usually correlated, but how morphology affects germination percentage and seedling growth is poorly understood. Here we explicitly separate these effects for nine populations of the dimorphic species Tragopogon pratensis subsp. pratensis. Larger seeds yielded higher germination percentages, yet seed morphology had no additional direct effect on germination. Neither seed size nor seed morphology affected seedling growth. Neither germination nor seedling growth varied among populations, but seed head varied significantly. Results show that germination is mainly controlled by seed size rather than by seed morphology. This study is one of the few to distinguish explicitly between seed size and seed morphology effects on ecological characteristics and suggests that seed dimorphism may exert its ecological effects predominantly through its correlated size.
\end{abstract}

Key words: Asteraceae; germination; The Netherlands; population; seed dimorphism; seed morphology; seed size; seedling growth.

Seed dimorphism is the phenomenon in which a single plant produces two seed types with different morphology and/or behavior. Seed dimorphism is common in Asteraceae (Harper, 1977) and may, for instance, be characterized by differences in embryo size or presence of a pappus (Venable and Levin, 1985). In several species, differentiation in morphology is accompanied by a difference in seed size (Maxwell et al., 1994; Imbert et al., 1997). Besides the difference in size and/or morphology, the two seed types can also differ in dispersal characteristics, dormancy, and germination requirements (McEvoy, 1984; Venable and Levin, 1985; Maxwell et al., 1994; Zhang, 1994). In Asteraceae, reduced dispersability and delayed germination are ascribed to peripheral, sometimes dark-colored, relatively heavy seeds, whereas distant dispersal and quick germination are associated with the central, pale, and lighter seeds (McEvoy, 1984; McGinley, 1989; Maxwell et al., 1994; Imbert and Ronce, 2001). According to Imbert (2002) seed polymorphism is used by plants to cope with differences in their microhabitats; central and peripheral seeds of Salicornia europaea (L.), for instance, respond differently to salt concentration.

In spite of the large number of studies, it remains unclear to what extent seed size and seed morphology independently affect ecological characteristics such as germination and seedling performance (Zhang, 1993). Many studies have focused on the effects of seed size: e.g., on germination and seedling characteristics between species (Leishman et al., 1995; Jakobsson and Eriksson, 2000), on colonization ability (Lopez et al., 2000; Gibson, 2001), and on variation within species (Thompson, 1984; Wulff, 1986). However, we find no studies

\footnotetext{
${ }^{1}$ Manuscript received 7 May 2004; revision accepted 1 December 2004.

The authors thank D. Matthies and J. Stuefer for their comments on and help with the statistical analysis of the data. Also thanks to Fulco Ludwig, Eelke Jongejans, Sara Gomez, and Josef Stuefer for comments on a previous version of the manuscript. This work was supported by the EU project TRANSPLANT (no. EVK2-CT-1999-000042).

${ }^{2}$ Author for correspondence (E-mail: L.Wienk@science.ru.nl.).
}

on dimorphic seeds that distinguish between the effects of seed morphology and the effects of seed size on the behavior of these seeds. Zhang (1993) is one of the few who investigated whether seed morphology or seed mass has a greater impact on germination percentage and seedling growth of Cakile edentula (Bigelow) Hook., but unlike for many other species, they found no differences in relation to seed morphology or mass.

Metapopulation models suggest that in some landscapes, selection pressures against short-distance dispersal may lead to lighter seeds. In severely fragmented landscapes, the reverse selection pressure can be found: all seeds that disperse from the safe site can be considered lost (Olivieri et al., 1995). Some models suggest that a stable coexistence of high- and lowdispersal phenotypes can develop due to these conflicting selection pressures on competition and dispersal (Ronce and Olivieri, 1997; Mathias et al., 2001; Mathias and Kisdi, 2002). Seed dimorphism may provide a solution to these demands (Imbert, 2002). Moreover, differences in the degree of dimorphism between populations can be expected because populations face different environmental conditions, such as variation in fragmentation or density. Whether variation in seed size and morphology separately affect population performance under different environmental conditions also remains unknown.

This study addresses whether seed size or seed morphology itself is the main factor that causes variation in germination percentage and seedling growth between two seed morphologies. Tragopogon pratensis subsp. pratensis (L.) was used as a model species because it produces dimorphic seeds that are relatively easy to distinguish. Complete seed heads were collected from nine populations of differing size, spatial isolation, and habitat to investigate population differences. We hypothesize that both seed size and seed morphology influence germination percentage and subsequent seedling growth. Germination and seedling growth were examined on both nutrientpoor and nutrient-rich soils and under both low and high ratios of red : far red light (R : FR) because some effects of seed 
TABLE 1. The location, habitat, effective population size (number of flowering individuals), and estimated degree of isolation (distance to next population) are shown per population of Tragopogon pratensis.

\begin{tabular}{|c|c|c|c|c|c|}
\hline \multirow[b]{2}{*}{ Site } & \multicolumn{2}{|c|}{ Coordinates } & \multirow[b]{2}{*}{ Habitat } & \multirow{2}{*}{$\begin{array}{c}\text { Effective } \\
\text { population size }\end{array}$} & \multirow{2}{*}{$\begin{array}{l}\text { Estimated } \\
\text { degree of } \\
\text { isolation }\end{array}$} \\
\hline & $\mathrm{N}$ & E & & & \\
\hline B1 & $51^{\circ} 53^{\prime} 17^{\prime \prime}$ & $05^{\circ} 51^{\prime} 27^{\prime \prime}$ & Roadside & $50-100$ & $\pm 250 \mathrm{~m}$ \\
\hline B2 & $51^{\circ} 53^{\prime} 33^{\prime \prime}$ & $05^{\circ} 51^{\prime} 55^{\prime \prime}$ & Roadside & $50-100$ & $\pm 250 \mathrm{~m}$ \\
\hline $\mathrm{Cr}$ & $51^{\circ} 53^{\prime} 33^{\prime \prime}$ & $05^{\circ} 51^{\prime} 55^{\prime \prime}$ & Dike & $50-100$ & $\pm 500 \mathrm{~m}$ \\
\hline Ма & $51^{\circ} 49^{\prime} 36^{\prime \prime}$ & $05^{\circ} 48^{\prime} 25^{\prime \prime}$ & Roadside & $50-100$ & $\pm 500 \mathrm{~m}$ \\
\hline NR & $51^{\circ} 49^{\prime} 41^{\prime \prime}$ & $05^{\circ} 17^{\prime} 06^{\prime \prime}$ & Meadow & $>2500$ & $>1000 \mathrm{~m}$ \\
\hline
\end{tabular}

size or morphology may become apparent only under unfavorable conditions (Gross, 1984; Maranon and Grubb, 1993; Leishman and Westoby, 1994; Vaughton and Ramsey, 1998).

\section{MATERIALS AND METHODS}

Plant material-Tragopogon pratensis subsp. pratensis (L.) occurs on roadside verges, dikes, and ruderal places on different soil types, from clay to sand and gravel (Weeda et al., 1991). The species is monocarpic and flowers from the end of May until the end of July. Tragopogon pratensis produces two seed types that differ in color and shape. The dark seeds are slightly curved, and their surface is rough. The pale seeds are straighter, and their surface is smoother. Dark seeds are produced on the peripheral ridge of the seed head, and pale seeds are produced in the central part. Both seed types are dispersed by wind, with the aid of a large pappus. The seeds used in this study were collected from nine populations in June 2002 (Table 1). The populations differ in size and degree of isolation (i.e., distance to the closest neighboring population). From each population, one seed head from 10 different individuals was collected.

Experimental setup - The seeds were weighed individually, without the pappus, on a Sartorius M2P microbalance (with an accuracy of $0.001 \mathrm{mg}$ ) and assigned to the "dark" (dark colored with a rough surface) or the "pale" morphology (light colored with smooth surface) or to the "empty" class (not developed, small pappus). The dark and pale seeds were stored individually in paper envelopes at room temperature. The number of ripe seeds per seed head ranged from 31 to 76 . For each of five seed heads per population, 12 dark and 12 pale seeds were selected for the germination experiment in July 2002 ; the seeds closest to the average mass of the morphology type of that seed head were selected.

Six trays containing 96 pots $\left(9 \mathrm{~cm}^{3}\right)$ were filled with sand (nutrient-poor substrate), and another six trays were filled with potting compost (nutrientrich substrate). In each tray, 45 dark and 45 pale seeds, one dark and one pale from each seed head. were placed randomly on the surface of the pots. The trays were then placed in a climate chamber maintained at $19 \pm 1{ }^{\circ} \mathrm{C}$, with $16 \mathrm{~h}$ light and $8 \mathrm{~h}$ dark per day. Three trays filled with sand and three trays filled with potting compost were put under white light in combination with far-red light (light bulbs; Paulmann Schwarzlicht, $75 \mathrm{~W}$ ); the remaining trays were put under white light (light bulbs; Philips TLD 36 W/840). The R : FR ratio of the far-red light bulbs in combination with white light was 0.2 , the $\mathrm{R}$ : FR ratio of the white light was 9 , and the light intensity was $80 \mu \mathrm{mol}$ $\cdot \mathrm{m}^{-2} \cdot \mathrm{s}^{-1}$. A light-impermeable screen was placed between the Far-Red (FR) and white (wt) light group. A Plexiglas plate was placed under the light bulbs to prevent heating the seeds. Germination was recorded daily for $20 \mathrm{~d}$. Seeds were considered to have germinated as soon as cotyledons emerged above the soil. The seeds, and later the seedlings, were watered regularly. Starting $3 \mathrm{~d}$ after germination and continuing at least every other day, the length of the longest leaf of each seedling was measured.
Data analysis - To determine whether the seeds were dimorphic with respect to seed mass, a one-way analysis of variance (ANOVA) was performed for each of the nine populations. Whether the proportion of the three classes (dark, light, and empty) varied among populations and whether dark and light seed types differed in seed size between populations was also tested with a one-way ANOVA. The effect of the light treatment on germination was evaluated with a $\chi^{2}$ test. A logistic regression, using seed mass as a covariable, was used to determine the effects of seed morphology, soil type, and population on germination percentage.

Differences in stem length were tested with ANCOVA using seed mass as a covariable. The main effects where soil type, population, seed head, and morphology. Seed head was considered nested within population. All tests were carried out with SAS, version 6 (SAS Institute, 1990).

\section{RESULTS}

Seed dimorphism-All nine populations produced dimorphic seeds with respect to seed size, and the dark seeds were heavier than the pale seeds (Fig. 1A). The individual seed masses on a seed head showed a bimodal distribution (data not shown) comparable to the distribution patterns of Tragopogon dubius seeds (McGinley, 1989). This pattern was found in all seed heads of all populations. Only occasionally was the difference between dark and pale seeds not obvious and an intermediate form was observed: a pale color, but a rough surface. We excluded these seed heads from further analyses.

Seed size differed greatly among populations with respect to dark and pale morphologies $(F=58.84, P<0.0001$ and $F=90.67, P<0.0001$, respectively). The average mass of pale seeds of some populations was similar to the average mass of dark seeds of other populations (Fig. 1A). Differences in seed size were not related to population size or distance to the next population.

The proportion of dark seeds on a seed head did not differ among populations and averaged $42.1 \% \pm 0.81(F=1.67, P$ $>0.05$; Fig. 1B). The proportions of pale and empty seeds, however, varied significantly among populations $(F=3.97, P$ $<0.001$ and $F=2.40, P<0.05$, respectively). No relationship was found between seed size and seed number per seed head (data not shown).

Germination-Germination percentage in white light was $47.1 \%$ after 20 days, but only $0.74 \%$ germinated under light with low R : FR ratio ( $\chi^{2}=88.64, P<0.0001$; Fig. 2 A). Because so few seedlings (only four) grew in the FR group, this group was excluded from further analysis. The far-red light bulbs were switched off at the end of the experiment to 


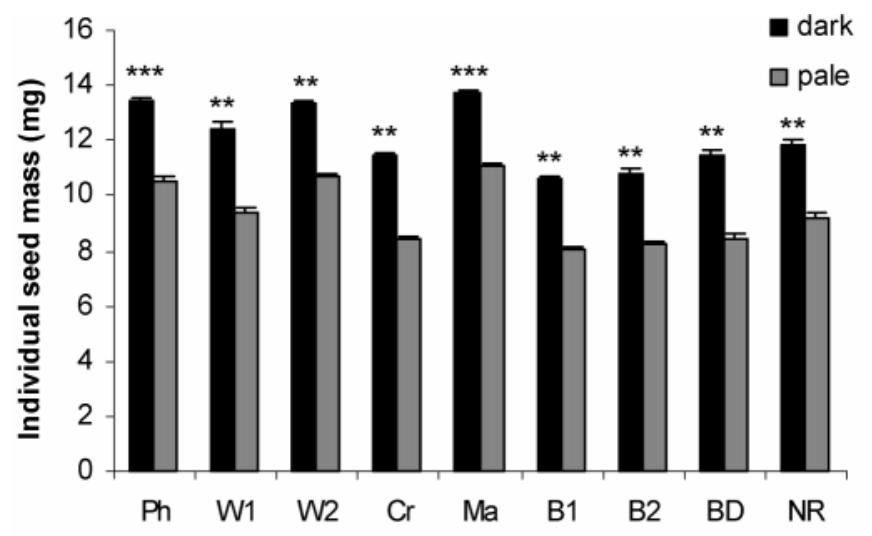

A Population

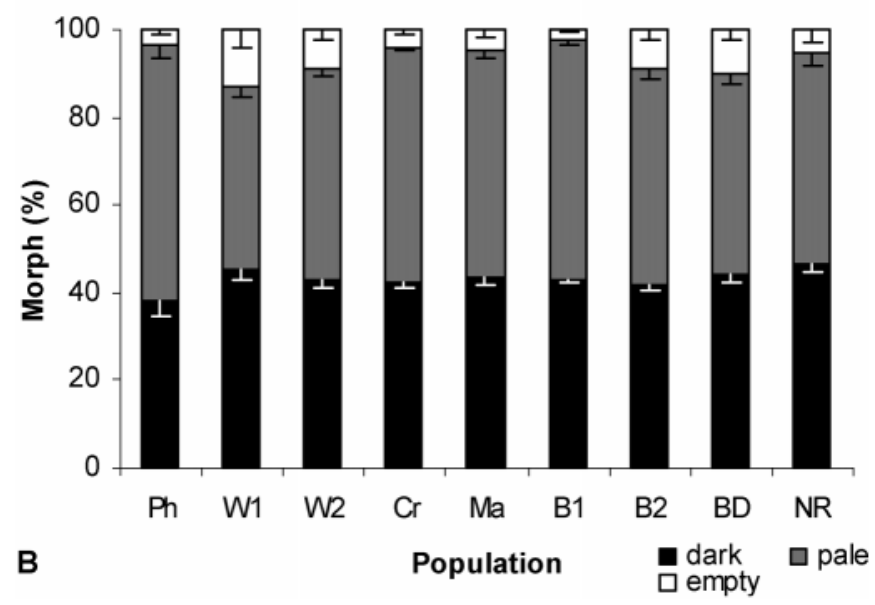

Fig. 1. Seed characteristics of nine populations of Tragopogon pratensis. (A) The average seed mass ( \pm SE) of both dark and pale morphologies per population. Seed dimorphism with respect to seed mass is significant between all populations $(P<0.01 * *, P<0.001 * * *)$. Populations are arranged from small (Ph) to large (NR) (see Table 1). (B) Percentage ( \pm SE) dark, pale, and empty seeds averaged for all seed heads $(N=10)$ per population. Percentage dark seeds is constant at $42.9 \% \pm 0.79(F=1.67, P>0.05)$.

test whether the seeds in the FR group were viable, and $40 \mathrm{~d}$ later, $61.3 \%$ had germinated.

In white light, dark seeds had a higher germination percentage than pale seeds, $65.5 \%$ and $29.7 \%$, respectively Fig. 2A). This effect could be entirely attributed to seed size; seed morphology did not influence germination percentage (Table 2 ). The probability of germination thus increased with increased seed size (Fig. 2B).

Seed head, however, did influence germination (Table 2), indicating that seeds from different individuals (mother plants) had different germination percentages, independent of seed size. Population had no significant effect on germination; differences between populations could be explained entirely by differences in seed size.

Growth-Seedlings remained shorter on nutrient-poor than on nutrient-rich soil (Fig. 3, Table 2). The first true leaf overgrows the cotyledon on nutrient-rich soil after $15 \mathrm{~d}$. This leaf is also formed on nutrient-poor soil, but it does not overgrow the cotyledon. Furthermore, seedling length was not affected
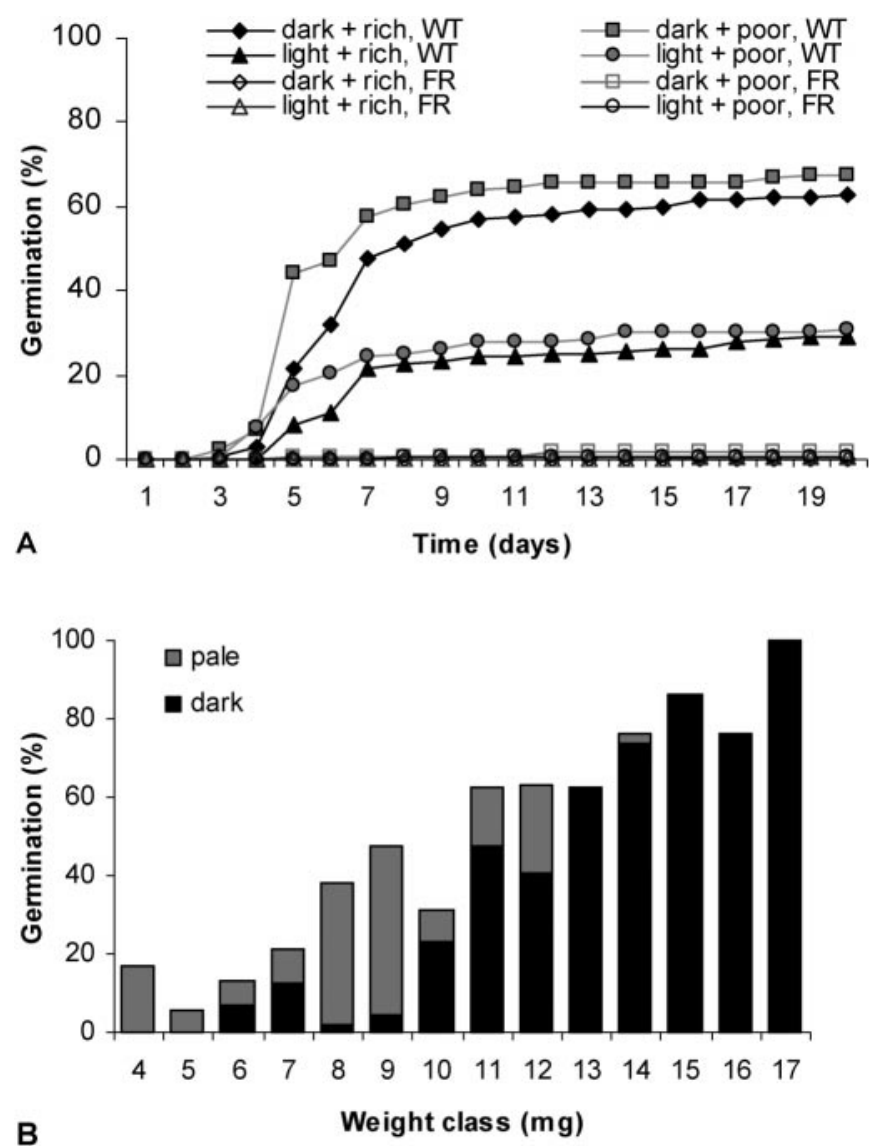

Fig. 2. (A) Germination rate of dark and pale seeds from the dimorphic Tragopogon pratensis sown on nutrient-rich and nutrient-poor soils and under white (wt) and far red (FR) light in a growth chamber $(N=12$ of each morph per seed head, $N=5$ seed heads per population). Seeds hardly germinated under FR light. (B) Total germination percentage per seed mass class of all populations on both soil types under white light are shown per morphology. Germination percentage increased with seed size $\left(\chi^{2}=10.37, P<0.005\right)$.

by seed size, morphology, or population (Table 2). Seed head, however, did significantly affect seedling length. In addition, all interactions with seed heads significantly affected seedling growth, indicating that seedlings arising from seeds from different individuals (mother plants) behaved differently with respect to growth. These differences between individuals vary between the two soil types and morphologies. Thus, seedlings originating from one individual may grow taller on nutrientrich soil than seedlings from another individual. Furthermore, for some seed heads, seedlings from pale seeds grew taller than seedlings from dark seeds and vice versa. However, no pattern in these differences emerged.

\section{DISCUSSION}

Although much work has been done on seed dimorphism, it is largely unknown to what extent seed size and seed morphology separately affect germination percentage and seedling growth and how this differs among populations of the same species. Here we show for Tragopogon pratensis subsp. pratensis that variation in seed size is the main causal agent affecting germination behavior and that morphology has no effect. 
TABLE 2. Statistical analysis of the effects of different parameters on germination (logistic regression) and seedling length (ANCOVA) of Tragopogon pratensis. Seed head is nested in population only for the ANCOVA and not for the logistic regression. The interactions with seed head are not tested for germination, because only a limited number of interactions are possible for the logistic regression.

\begin{tabular}{|c|c|c|c|c|c|c|c|}
\hline \multirow[b]{2}{*}{ Parameters } & \multicolumn{3}{|c|}{ Germination } & \multicolumn{4}{|c|}{ Seedling length } \\
\hline & df & $x^{2}$ & $P$ & df & $\begin{array}{l}\text { Mean } \\
\text { square }\end{array}$ & $F$ & $P$ \\
\hline Seed size & 1 & 10.37 & 0.001 & 1 & 117.57 & 0.3 & 0.584 \\
\hline Seed head (population) & 36 & 54.56 & 0.024 & 34 & 858.21 & 2.2 & 0.001 \\
\hline Morphology & 1 & 0.01 & 0.916 & 1 & 32.32 & 0.04 & 0.851 \\
\hline Morphology $\times$ population & 8 & 5.59 & 0.693 & 7 & 848.96 & 0.93 & 0.509 \\
\hline Soil $\times$ seed head (population) & & & & 26 & 1309.96 & 3.35 & $<0.0001$ \\
\hline Morphology $\times$ soil & 1 & 0.00 & 0.958 & 1 & 732.89 & 0.45 & 0.524 \\
\hline Morphology $\times$ soil $\times$ population & 8 & 8.14 & 0.420 & 7 & 1626.46 & 1.79 & 0.195 \\
\hline Morphology $\times$ soil $\times$ seed head (population) & & & & 10 & 908.44 & 2.33 & 0.015 \\
\hline Error & & & & 128 & 390.61 & & \\
\hline
\end{tabular}

In Tragopogon pratensis, dark (i.e., peripheral) seeds were heavier than pale (i.e., central) seeds within seed heads. The proportion of dark seeds was remarkably constant within as well as among populations. A few other studies did find a relationship between proportion of a certain morphology and environmental stress (Imbert and Ronce, 2001, and references therein). Differences in proportion of morphologies could be expected for $T$. pratensis because the populations differed in size and degree of spatial isolation. Selection pressures for different seed morphologies may have been similar in different environments, or T. pratensis may not be plastic in its distribution of morphologies, as is the case for other dimorphic species (Imbert, 2002).

Light conditions had a dramatic effect on germination percentages. Cresswell and Grime (1981) found that T. pratensis seeds can germinate in the dark, but our results show that the seeds do not germinate under light with a low R : RF ratio. This is consistent with the pattern found in many species (Brunvatne, 1998; Van Hinsberg, 1998; Shichijo et al., 2001; Yirdaw and Leinonen, 2002). Although dark seeds germinated

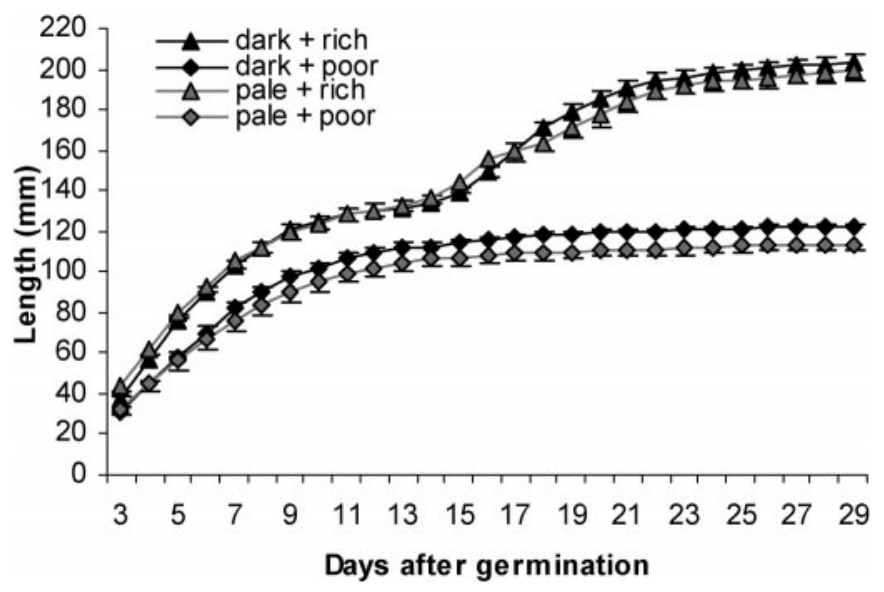

Fig. 3. Length of seedlings from dark or pale seeds of the dimorphic Tragopogon pratensis on nutrient-rich and nutrient-poor soils (mean for all populations). Error bars do not exceed the symbols. Seedlings on nutrientrich soil grew significantly taller $(F=330.07, P<0.0001)$, but morphology had no significant effect. better than pale seeds, this was only because dark seeds are larger. Seed size is the main factor determining germination percentage, as has frequently been reported for nondimorphic species (Winn, 1985; Hendrix and Trapp, 1992; Vaughton and Ramsey, 1998; Parciak, 2002). Differences in germination percentage between dimorphic seeds reported in previous studies (Venable and Levin, 1985; Venable et al., 1987; Imbert, 1999; El-Keblawy, 2003) may have resulted from differences in seed size rather than seed morphology. In addition to seed size, only seed head had a significant effect on germination percentage. This effect probably reflects genotypic (maternal) variation, because only one seed head was collected per individual plant.

According to Roach and Wulff (1987), maternal tissues surrounding the embryo, such as differences in the seed coat, can influence germination. Differences in seed content, such as starch and proteins, could also play a role in germination differences because physiological processes are involved in breaking dormancy and/or onset of germination (Vleeshouwers et al., 1995; Dyer, 2004). However, we are aware of only one laboratory study (Kristensen, 2003) that showed a negative relationship between mean germination time and protein content in Hordeum vulgare (L.), but it did not relate protein content to seed size. To our knowledge, why larger seeds have higher germination rates than smaller seeds is mostly unknown, and this certainly applies to the larger morphs in dimorphic seeds.

Seedling growth differed between the two soil types and among seed heads. No population, seed size, or seed morphology effect was found for seedling growth. Thus, although seed size is very important for germination, it does not affect seedling growth. This is different from many other species, in which larger seeds produce larger seedlings (Venable and Levin, 1985; Zhang, 1993; Maxwell et al., 1994). Imbert et al. (1997) found an effect of size only when seedlings were grown under competition. To simulate a stressful environment, we included a nutrient-poor treatment in our experiment, but seedling growth did not differentiate among seed sizes in this treatment either. In all the studies that did find an effect, embryo size of the seeds differed. Perhaps embryo sizes in $T$. pratensis are similar for different seed sizes, and the main component of variation in seed size is the pericarp, as in T. dubius (Maxwell et al., 1994). It could also be that seeds differ in endo- 
sperm content. Roach and Wulff (1987) argue that the female parent may play a more important role in determining endosperm characteristics than the male parent. Potential differences in endosperm content in $T$. pratensis seeds may therefore account for the differences in growth between seed heads.

Implications - The lack of effects of seed morphology on germination and seedling growth raises the question why $T$. pratensis produces dimorphic seeds at all. To maintain seed dimorphism, there must be an ecological difference between morphologies (Imbert et al., 1997). Seed morphology should therefore have ecological impacts other than on seedling growth or germination. Predation rates, for instance, may differ between the dark and pale seeds, but we are unaware of studies that have investigated this. Geritz (1998) proposed that if the attack rate of predators is related to seed size, seed size variation within an individual is favored. Consistent with this model, the dimorphism may also be an evolutionary stable strategy to maintain variation in morphology. The morphologies of $T$. pratensis differ in color as well as structure, as in T. dubius (Scop.) (Maxwell et al., 1994), which may require different handling and searching strategies for predators, e.g., dark seeds are less visible on a dark surface than pale seeds, and vice versa.

Alternatively, seed dimorphism may arise from ontogenetic constraints as described by Imbert (2002). The hypothesis of developmental constraints arising from the morphology of the floral axis (McGinley, 1989) of the seed head is consistent with our observation that the proportion of dark (or peripheral) morphologies is fixed among populations, in spite of seed size differences. However, developmental constraints do not exclude that there is, or has been, an adaptive value of seed dimorphism. Seed dimorphism may solve conflicting demands on dispersal (Ronce and Olivieri, 1997) and the risk of predation. It may also be that seed dimorphism has been advantageous in the past and that developmental constraints have simply conserved it.

\section{LITERATURE CITED}

BRunvatne, J. O. 1998. Influence of light quality on the germination of Betula papyrifera seeds. Scandinavian Journal of Forest Research 13: 324-330.

Cresswell, E. G., AND J. P. GRIME. 1981. Induction of a light requirement during seed development and its ecological consequences. Nature 291: 583-585.

DYER, A. R. 2004. Maternal and sibling factors induce dormancy in dimorphic seed pairs of Aegilops triuncialis. Plant Ecology 172: 211-218.

El-Keblawy, A. 2003. Effects of achene dimorphism on dormancy and progeny traits in the two ephemerals Hedypnois cretica and Crepis aspera (Asteraceae). Canadian Journal of Botany 81: 550-559.

GeritZ, S. A. H. 1998. Co-evolution of seed size and seed predation. Evolutionary Ecology 12: 891-911.

Gibson, J. P. 2001. Ecological and genetic comparison between ray and disc achene pools of the heteromorphic species Prionopsis ciliata (Asteraceae). International Journal of Plant Sciences 162: 137-145.

GRoss, K. L. 1984. Effects of seed size and growth form on seedling establishment of 6 monocarpic perennial plants. Journal of Ecology 72: 369387.

HARPer, J. L. 1977. Population biology of plants. Academic Press, London, $\mathrm{UK}$.

Hendrix, S. D., AND E. J. Trapp. 1992. Population demography of Pastinaca sativa (Apiaceae): effects of seed mass on emergence, survival, and recruitment. American Journal of Botany 79: 365-375.

IMBERT, E. 1999. The effects of achene dimorphism on the dispersal in time and space in Crepis sancta (Asteraceae). Canadian Journal of Botany 77: 508-513.
IMBERT, E. 2002. Ecological consequences and ontogeny of seed heteromorphism. Perspectives in Plant Ecology Evolution and Systematics 5: 1336.

Imbert, E., J. EsCARRE, AND J. LePART. 1997. Seed heteromorphism in Crepis sancta (Asteraceae): performance of two morphologies in different environments. Oikos 79: 325-332.

IMBERT, E., AND O. RonCE. 2001. Phenotypic plasticity for dispersal ability in the seed heteromorphic Crepis sancta (Asteraceae). Oikos 93: 126134.

JAKOBSSON, A., AND O. ERIKSSON. 2000. A comparative study of seed number, seed size, seedling size and recruitment in grassland plants. Oikos 88: 494-502.

Kristensen, L. 2003. Maternal effects due to organic and conventional growing conditions in spring barley (Hordeum vulgare). Biological Agriculture \& Horticulture 21: 195-208.

Leishman, M. R., AND M. Westoby. 1994. The role of seed size in seedling establishment in dry soil conditions-experimental evidence from semiarid species. Journal of Ecology 82: 249-258.

Leishman, M. R., M. Westoby, and E. Jurado. 1995. Correlates of seed size variation-a comparison among 5 temperate floras. Journal of Ecology 83: 517-529.

Lopez, M., J. M. Humara, A. Casares, and J. Majada. 2000. The effect of temperature and water stress on laboratory germination of Eucalyptus globulus Labill. seeds of different sizes. Annals of Forest Science 57: 245-250.

Maranon, T., AND P. J. GRUBB. 1993. Physiological basis and ecological significance of the seed size and relative growth rate relationship in Mediterranean annuals. Functional Ecology 7: 591-599.

Mathias, A., E. Kisdi, AND I. Olivieri. 2001. Divergent evolution of dispersal in a heterogeneous landscape. Evolution 55: 246-259.

Mathias, A., AND E. KisDi. 2002. Adaptive diversification of germination strategies. Proceedings of the Royal Society of London, Series B, Biological Sciences 269: 151-155.

Maxwell, C. D., A. Zobel, And D. Woodfine. 1994. Somatic polymorphism in the achenes of Tragopogon dubius. Canadian Journal of Botany 72: $1282-1288$.

McEvoy, P. B. 1984. Dormancy and dispersal in dimorphic achenes of tansy ragwort, Senecio-Jacobaea 1 (Compositae). Oecologia 61: 160-168.

MCGINLEY, M. A. 1989. Within and among plant variation in seed mass and pappus size in Tragopogon dubius. Canadian Journal of Botany 67: 1298-1304.

Olivieri, I., Y. MichalaKis, AND P. H. Gouyon. 1995. Metapopulation genetics and the evolution of dispersal. American Naturalist 146: 202-228.

PARCIAK, W. 2002. Environmental variation in seed number, size and dispersal of a fleshy-fruited plant. Ecology 83: 780-793.

RoAch, D. A., AND R. D. WULFF. 1987. Maternal effects in plants. Annual Review of Ecology and Systematics 18: 209-235.

Ronce, O., AND I. OLIVIERI. 1997. Evolution of reproductive effort in a metapopulation with local extinctions and ecological succession. American Naturalist 150: 220-249.

SAS InstituTE, INC. 1990. SAS/STAT user's guide, version 6, 4th ed. SAS Institute Inc., Cary, North Carolina, USA.

ShichiJo, C., K. Katada, O. Tanaka, And T. Hashimoto. 2001. Phytochrome A-mediated inhibition of germination in tomato. Planta 213: 764-769.

Thompson, J. N. 1984. Variation among individual seed masses in Lomatium Grayi (Umbelliferae) under controlled conditions: magnitude and partitioning of the variance. Ecology 65: 626-631.

VAn HinsBerG, A. 1998. Maternal and ambient environmental effects of light on germination in Plantago lanceolata: correlated responses to selection on leaf length. Functional Ecology 12: 825-833.

Vaughton, G., AND M. Ramsey. 1998. Sources and consequences of seed mass variation in Banksia marginata (Proteaceae). Journal of Ecology 86: 563-573.

Venable, D. L., AND D. A. LeVIN. 1985. Ecology of achene dimorphism in Heterotheca Latifolia. 1. Achene structure, germination and dispersal. Journal of Ecology 73: 133-145.

Venable, D. L., A. Búquez, G. Corral, E. Morales, and F. Espinosa. 1987. The ecology of seed heteromorphism in Heterosperma pinnatum in central Mexico. Ecology 68: 65-76.

Vleeshouwers, L. M., H. J. Bouwmeester, and C. M. Karssen. 1995. Redefining seed dormancy: an attempt to integrate physiology and ecology. Journal of Ecology 83: 1031-1037. 
Weeda, E. J., R. Westra, C. H. Westra, and T. Westra. 1991. De Nederlandse oecologische flora, wilde planten en hun relaties, vol. 4. KNNV Press, Utrecht, Netherlands.

WINN, A. A. 1985. Effects of seed size and microsite on seedling emergence of Prunella Vulgaris in 4 habitats. Journal of Ecology 73: 831-840.

WulfF, R. D. 1986. Seed size variation in Desmodium paniculatum. III. Effects on reproductive yield and competitive ability. Journal of Ecology 74: $115-121$.
YIRDAW, E., AND K. LEINONEN. 2002. Seed germination responses of four afromontane tree species to red/far-red ratio and temperature. Forest Ecology and Management 168: 53-61.

ZHANG, J. H. 1993. Seed dimorphism in relation to germination and growth of Cakile Edentula. Canadian Journal of Botany 71: 1231-1235.

ZHANG, J. H. 1994. Early seedling development in relation to seed mass and morph in Cakile Edentula. Canadian Journal of Botany 72: 402406. 